\title{
Use of a remotely controlled mechanical pump for coronary arteriography: a study of radiation exposure and quality implications
}

\author{
S C D Grant, E B Faragher, A P Hufton, D H Bennett
}

\begin{abstract}
Background-Exposure to radiation is a hazard of invasive cardiology. To minimise the risk it is essential to keep the doses received as low as possible.

Aim-To assess the effect on cardiologist radiation exposure and the quality of coronary artery opacification of the use of a remotely controlled mechanical pump for coronary arteriography. A secondary aim was to assess any disadvantages and safety.

Methods-319 patients were randomised to have coronary arteriography carried out with contrast injected either by hand or by a remotely controlled mechanical pump. Six cardiologists participated: two catheter laboratories were used and both brachial and femoral approaches were included. The exposure of the cardiologists to radiation was assessed by film badge dosimetry. The badges were worn on the hat. The total time for the procedure, screening time, the dose-area product meter reading, and any complications were recorded for each examination. The quality of arterial opacification was reported on a scale of $0-5$.

Results-The mean radiation dose per procedure was $0.011 \mathrm{mSv}$ for hand injection of contrast and $0.005 \mathrm{mSv}$ for mechanical injection $(p<0.01)$. There were no differences in procedure times or screening times. There were no complications attributable to mechanical injection. Arterial opacification was not significantly different in the two groups (4.01 $v 4.03$ for the left coronary artery, $4.68 v 4.78$ for the right coronary artery). The right coronary artery was consistently better opacified than the left by both techniques $(4.59 v 3.89, \mathrm{p}<0.001)$.

Conclusions-Use of a remotely controlled mechanical pump for coronary arteriography reduced cardiologist radiation exposure by half. It was not associated with any inconvenience, expense, or complications and produced arterial opacification at least as good as injection by hand.
\end{abstract}

(Br Heart f 1993;70:479-484)
The $x$ ray exposure of catheter laboratory staff depends upon proximity to the $x$ ray source and patient, use of shielding, and on the time spent in the catheter laboratory. For each procedure the highest staff exposure is that of the cardiologist.

As diagnostic and interventional practice expands increasing radiation exposure is likely. Levels of exposure are a cause of concern, and the British Cardiac Society recently set up a working party to look into the subject. ${ }^{1}$ The report of the working groups appears on pages 489-96 of this issue.

We evaluated the use of a technique that increases the distance between the cardiologist and the source of $x$ rays during coronary arteriography.

\section{Patients and methods}

PATIENTS

All patients undergoing left ventricular angiography and coronary arteriography performed by the participating operators during the period of the study (18 April 1991 to 31 December 1991) were eligible for randomisation. Patients undergoing additional procedures, such as aortography, arteriography of grafts, or right heart catheterisation, were excluded. Five hundred and seventy eight patients underwent left ventriculography and coronary arteriography without other procedures: 259 were not randomised because of operational pressures.

\section{RANDOMISATION}

After the operator, catheter laboratory, and access route were determined, patients were randomised by selection of a sealed envelope, within which the injection mode was indicated.

Randomisation was stratified to allow for the use of two different catheter laboratories and the brachial and femoral arterial access routes. Tables 1 and 2 show the characteristics of the groups randomised to hand and mechanical injection.

\section{ARTERIOGRAPHY}

Six cardiologists participated in the study. Both the brachial and femoral arterial access routes were used. Catheterisation was 
Table 1 Characteristics ( $n(\%)$ ) of the two groups used to compare radiation doses with hand and mechanical injection

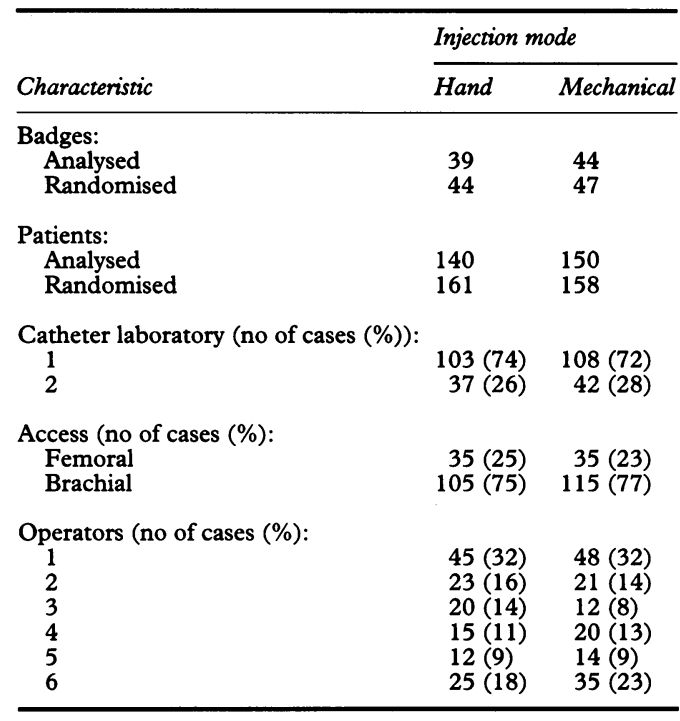

performed in one of two catheter laboratories (table 3). The technique used for injection of contrast into the coronary arteries has been described in detail elsewhere. ${ }^{2}$ In brief, for those randomised to hand injection the coronary catheter was introduced into the coronary ostium and contrast was injected during cineangiography by the cardiologist from a hand-held syringe. For those randomised to mechanical injection the approximate size of the coronary artery was established by a small test injection given by hand. A suitable

Table 2 Characteristics ( $n(\%)$ ) of the two groups in which quality of coronary artery opacification was compared

\begin{tabular}{|c|c|c|}
\hline \multirow[b]{2}{*}{ Characteristic } & \multicolumn{2}{|l|}{ Injection mode } \\
\hline & Hand & Mechanical \\
\hline $\begin{array}{l}\text { Patients: } \\
\text { Analysed } \\
\text { Randomised }\end{array}$ & $\begin{array}{l}157 \\
161\end{array}$ & $\begin{array}{l}155 \\
158\end{array}$ \\
\hline $\begin{array}{l}\text { Brachial: } \\
\text { Castillo } \\
\text { Sones } \\
\text { TB } \\
\text { NIH } \\
\text { Unknown }\end{array}$ & $\begin{array}{c}78(50) \\
22(14) \\
15(10) \\
0(0) \\
1(<1)\end{array}$ & $\begin{array}{l}83(54) \\
26(17) \\
7(5) \\
2(1) \\
1(<1)\end{array}$ \\
\hline $\begin{array}{l}\text { Femoral: } \\
\text { Judkins } \\
\text { TF } \\
\text { Unknown }\end{array}$ & $\begin{array}{c}40(25) \\
1(<1) \\
0(0)\end{array}$ & $\begin{aligned} 31 & (20) \\
4 & (3) \\
1 & (<1)\end{aligned}$ \\
\hline $\begin{array}{l}\text { Operator: } \\
1 \\
2 \\
3 \\
4 \\
5 \\
6\end{array}$ & $\begin{array}{l}47(30) \\
28(18) \\
25(16) \\
15(10) \\
12(8) \\
30(19)\end{array}$ & $\begin{array}{l}48(31) \\
21(14) \\
12(8) \\
20(13) \\
14(9) \\
40(26)\end{array}$ \\
\hline $\begin{array}{l}\text { Catheter labora } \\
1 \\
2\end{array}$ & $\begin{array}{r}113(72) \\
44(28)\end{array}$ & $\begin{array}{r}114(74) \\
41(26)\end{array}$ \\
\hline $\begin{array}{l}\text { Catheter gauge: } \\
\text { Mean FG } \\
95 \% \text { CI }\end{array}$ & $\begin{array}{l}6.83 \\
6.70 \text { to } 6.95\end{array}$ & $\begin{array}{l}6.93 \\
6.80 \text { to } 7.05\end{array}$ \\
\hline $\begin{array}{l}\text { Contrast volum } \\
\text { Mean } \\
95 \% \text { CI }\end{array}$ & $\begin{array}{l}102 \\
99 \cdot 5 \text { to } 104 \cdot 2\end{array}$ & $\begin{array}{l}102 \\
99 \cdot 5 \text { to } 104 \cdot 8\end{array}$ \\
\hline
\end{tabular}

TB, more than one type of catheter type from the brachia route; TF, more than one type of catheter from the femoral route; FG, French gauge.
Table 3 Characteristics of the two catheter laboratories

\begin{tabular}{lll}
\hline Characteristic & Laboratory 1 & Laboratory 2 \\
\hline Generator & Phillips, & Siemens, \\
& Optimus M200 & Polydoros 10 \\
C-arm (single plane) & Polydiagnost C & Angioskop \\
Pulse width (ms) & $5 \cdot 0-6 \cdot 4$ & $6 \cdot 0$ \\
Maximum kV & 125 & 125 \\
Frame rate (/s) & 50 & 30 \\
Intensifier & 210 & 180 \\
conversion factor & & \\
(cd.m $\left.{ }^{-2} \cdot \mathrm{mR}^{-1} \cdot \mathrm{s}\right)$ & & \\
\hline
\end{tabular}

volume and flow rate of contrast were selected $(7 \mathrm{ml}$ at $5 \mathrm{ml} / \mathrm{s}$ pressure rise time $0.5 \mathrm{~s}$ for normal sized arteries) and contrast was injected from a mark IV Medrad pump. The pump, catheter, pressure monitoring line, and test syringe were connected by a four-port manifold. Operators retired from the $x$ ray source during cine filming to a minimum distance of 2 metres.

\section{MEASUREMENT OF RADIATION EXPOSURE}

Radiation exposure was assessed by film badge dosimetry. Badges were attached to the cardiologist's hat above the left eye. There were five monitoring periods of 4-8 weeks with film badges being changed for each period. Film badges were processed by the dosimetry service approved by the North Western Medical Physics Department.

Ninety one badges were used: eight badges representing 29 cases (five badges representing 21 cases randomised to hand injection and three badges representing eight cases randomised to mechanical injection) were used incorrectly. Data from these badges were excluded from further analysis. Overall data are presented in tables 1 and 5 as well as the data used for analysis.

\section{DETAILS AND COMPLICATIONS OF THE PROCEDURES}

The following details of each procedure were recorded: date, operator, laboratory, arterial access route, injection mode, whether hand injection was used during part of a procedure against the randomised code (and the reason for this), time for procedure (from first incision to last skin suture for brachial route, from first skin puncture with Seldinger needle to removal of last catheter for femoral route), screening time, dose-area product meter reading (DAPM) a measure of emitted radiation in rad. $\mathrm{cm}^{2}$ ), contrast volume, and number and type of catheters used. Any complications were also recorded.

\section{ARTERIAL OPACIFICATION}

Arterial opacification was assessed from the cinefilm at a later stage by one of us (SG), who was unaware of the mode of injection at the time of reporting. A scale was devised for quality of arterial opacification (table 4), similar to that used by others. ${ }^{34}$ Each cineangiographic projection was assessed according to the scale. The mean value for opacification of the left and right coronary arteries was calculated and this used for the analysis.

Seven of the 319 cases were excluded from analysis of arterial opacity: in four cases no 
Table 4 Numerical scoring system used for grading coronary artery opacity

\begin{tabular}{ll}
\hline Score & Description of coronary artery $(C A)$ \\
\hline 0 & Contrast injected CA not seen \\
1 & CA visible but poorly seen \\
2 & CA opacified but inadequate for diagnosis \\
3 & Adequate for diagnosis but inconsistent \\
opacity or streaming seen \\
4 & Good quality opacification little mixing or \\
5 & streaming \\
& Excellent quality more contrast or faster \\
\hline
\end{tabular}

coronary arteriograms were performed, even though this had been the intention at the start of the procedure; in two the films could not be found; and one case was a pacemaker procedure included in error.

\section{STATISTICAL ANALYSIS}

The relations between the principal outcome measures (radiation exposure per case and arterial opacity) and procedural details (injection mode, operator, route of arterial access, laboratory, catheter gauge and type, contrast volume, procedure time) were evaluated by standard model fitting (regression) methods. ${ }^{5}$ The radiation data were approximately normally distributed. The arterial opacity scores were subjected to a logistic transformation for analysis. The adequacy of all model fits was confirmed by constructing normal probability plots. All computations were performed with the GLIM 3.77 statistical computer package.

\section{Results}

COMPARISON OF HAND AND MECHANICAL INJECTION.

There was a significant difference in the radiation exposure between the two injection techniques (hand $0.011 \mathrm{mSv} / \mathrm{case}$, mechanical $0.005 \mathrm{mSv} /$ case, $\mathrm{p}<0.01$ (table 5))

Table 5 Comparison of results for hand and mechanical injection groups

\begin{tabular}{|c|c|c|c|}
\hline & \multicolumn{3}{|l|}{ Injection mode } \\
\hline & Hand & Mechanical & $t(d f)$ and $p$ value \\
\hline $\begin{array}{l}\text { Total radiation (mSv): } \\
\text { From badges analysed } \\
\text { From badges randomised }\end{array}$ & $\begin{array}{l}1.22 \\
1.31\end{array}$ & $\begin{array}{l}0.58 \\
0.60\end{array}$ & \\
\hline $\begin{array}{l}\text { Dose per case }(\mathrm{mSv}): \\
\text { Mean } \\
95 \% \mathrm{CI}\end{array}$ & $\begin{array}{l}0.011 \\
0.0083 \text { to } 0.138\end{array}$ & $\begin{array}{l}0.0052 \\
0.0026 \text { to } 0.0078\end{array}$ & $\begin{array}{l}t(81)=3.059 \\
p<0.01\end{array}$ \\
\hline $\begin{array}{l}\text { Opacity score LCA: } \\
\text { Mean } \\
95 \% \mathrm{CI}\end{array}$ & $\begin{array}{l}4 \cdot 01 \\
3 \cdot 89 \text { to } 4 \cdot 12\end{array}$ & $\begin{array}{l}4 \cdot 03 \\
3 \cdot 91 \text { to } 4 \cdot 14\end{array}$ & $\begin{array}{l}t(299)=0 \cdot 18 \\
\text { NS }\end{array}$ \\
\hline $\begin{array}{l}\text { Opacity score RCA: } \\
\text { Mean } \\
95 \% \mathrm{CI}\end{array}$ & $\begin{array}{l}4 \cdot 68 \\
4 \cdot 60 \text { to } 4 \cdot 75\end{array}$ & $\begin{array}{l}4 \cdot 73 \\
4 \cdot 65 \text { to } 4 \cdot 80\end{array}$ & $\begin{array}{l}t(299)=0.89 \\
\text { NS }\end{array}$ \\
\hline $\begin{array}{l}\text { Procedure time (min): } \\
\text { Mean } \\
95 \% \text { CI }\end{array}$ & $\begin{array}{l}20 \cdot 08 \\
17 \cdot 81 \text { to } 22 \cdot 74\end{array}$ & $\begin{array}{l}19 \cdot 48 \\
17 \cdot 16 \text { to } 21 \cdot 80\end{array}$ & $\begin{array}{l}t(81)=0.474 \\
\text { NS }\end{array}$ \\
\hline $\begin{array}{l}\text { Screening time (min): } \\
\text { Mean } \\
95 \% \mathrm{CI}\end{array}$ & $\begin{array}{l}2.85 \\
1.91 \text { to } 3.79\end{array}$ & $\begin{array}{l}2.60 \\
1.71 \text { to } 3.48\end{array}$ & $\begin{array}{l}\mathrm{t}(81)=0.390 \\
\text { NS }\end{array}$ \\
\hline $\begin{array}{l}\text { DAPM Reading }\left(\text { Rad. } \mathrm{cm}^{2}\right): \\
\text { Mean } \\
95 \% \text { CI } \\
\text { Complications }\end{array}$ & $\begin{array}{l}4000 \\
3568 \text { to } 4432 \\
3 \text { minor, } 1 \text { major (CABG) }\end{array}$ & $\begin{array}{l}4510 \\
4103 \text { to } 4917 \\
1 \text { minor, } 0 \text { major }\end{array}$ & $\begin{array}{l}t(81)=1.719 \\
0.05<p<0.10 \\
\star\end{array}$ \\
\hline
\end{tabular}

*Tabulated separately in table 6 .

Values for stated degrees of freedom are shown with corresponding $p$ values.
Table 6 Complications seen during the study

\begin{tabular}{l}
\hline Route $^{*}$ Complication \\
\hline Brachial: \\
Mechanical injection: \\
(1) Brachial artery dissection, case abandoned \\
Hand injection: \\
$\begin{array}{ll}\text { (1) Pericardial injection VF, absent pulse } \\
\text { (2) } & \text { Subclavian artery dissection, case abandoned } \\
\text { (3) } & \text { Bleeding from arteriotomy } \\
\text { (4) } & \text { Urgent CABG }\end{array}$
\end{tabular}

*There were no complications when the femoral route was used.

There was no difference between the two groups in terms of screening time, procedure time, or quality of opacification of the right or left coronary artery. There were four complications in the hand injected group compared with one in the mechanical injection group (table 6).

\section{OTHER FINDINGS}

\section{Comparison between operators}

There were significant differences between the operators in radiation exposure, procedure time, screening time, DAPM reading, and left coronary opacity score (table 7).

\section{Comparison between catheter laboratories}

There were statistically significant differences between the laboratories in DAPM reading and radiation exposure per case, with catheter laboratory number 2 having higher values in both instances (table 8). There were no significant differences in procedure time, screening time, or arterial opacification.

\section{Comparison between femoral and brachial access routes}

The brachial access route was used in 220 $(76 \%)$ cases. The femoral route had statistically significantly shorter procedure times than the brachial route $(15.46 \mathrm{~min} v 21.75$ min; table 9). The brachial route produced a higher opacity score and had a larger mean catheter gauge than the femoral route. The two access routes were largely used by different operators (table 7). There were no significant differences in radiation exposure, screening time, or DAPM reading between the two routes.

\section{Comparison of different catheter types}

The NIH catheter gave the highest arterial opacity scores but was only used for two cases and is not in general use for coronary arteriography (table 10). Castillo, Sones, and TB (TB indicates the use of more than one catheter type by the brachial route-and thus suggests a difficult coronary intubation) catheters were not significantly different from each other. These three catheter types all produced statistically significantly superior opacity scores than Judkins catheters. TF catheters (more than one catheter type from the femoral route) had a mean arterial opacity value similar to the Judkins catheter but this was not significantly different from the other types because the small number of observations gave wide confidence intervals. 
Table 7 Comparison of results for different operators

\begin{tabular}{|c|c|c|c|c|c|c|c|c|c|c|c|c|}
\hline$O P$ & $G R$ & No & $\begin{array}{l}\text { Brachial } \\
(\%)\end{array}$ & $\begin{array}{l}\text { Hand } \\
(\%)\end{array}$ & $\begin{array}{l}\text { Lab } 1 \\
(\%)\end{array}$ & $\begin{array}{l}\text { Cath gauge } \\
(F G)\end{array}$ & $\begin{array}{l}\text { Doselcase } \\
(m S v)\end{array}$ & $\begin{array}{l}\text { Procedure time } \\
\text { (min) }\end{array}$ & $\begin{array}{l}\text { Screening } \\
\text { time (min) }\end{array}$ & $\begin{array}{l}D A P M \text { reading } \\
\left({\left.\mathrm{rad} . \mathrm{cm}^{2}\right)}^{2}\right.\end{array}$ & $\begin{array}{l}\text { LCA opacity } \\
\text { score }\end{array}$ & $\begin{array}{l}R C A \\
\text { score }\end{array}$ \\
\hline 1 & C & 93 & 100 & 48 & 81 & $\begin{array}{l}7 \cdot 00 \\
(7 \cdot 99 \text { to } 7 \cdot 01)\end{array}$ & $\begin{array}{l}0.0048 \\
(0.0005 \text { to } 0.0091)\end{array}$ & $\begin{array}{l}16.80 \\
(13.39 \text { to } 20.22)\end{array}$ & $\begin{array}{l}1 \cdot 824 \\
(0.4059 \text { to } 3 \cdot 242)\end{array}$ & $\begin{array}{l}3929 \\
(3244 \text { to } 4614)\end{array}$ & $\begin{array}{l}4 \cdot 12 \\
(3 \cdot 98 \text { to } 4 \cdot 25)\end{array}$ & $\begin{array}{l}4 \cdot 77 \\
(4 \cdot 68 \text { to } 4 \cdot 85)\end{array}$ \\
\hline 2 & C & 44 & 0 & 52 & 86 & $\begin{array}{l}6 \cdot 00 \\
(6.00 \text { to } 6 \cdot 00)\end{array}$ & $\begin{array}{l}0 \cdot 0047 \\
(0 \text { to } 0.0102)\end{array}$ & $\begin{array}{l}16 \cdot 56 \\
(12 \cdot 15 \text { to } 20.97)\end{array}$ & $\begin{array}{l}2 \cdot 341 \\
(0 \cdot 5099 \text { to } 4 \cdot 171)\end{array}$ & $\begin{array}{l}3752 \\
(2868 \text { to } 4637)\end{array}$ & $\begin{array}{l}3 \cdot 54 \\
(3 \cdot 30 \text { to } 3 \cdot 76)\end{array}$ & $\begin{array}{l}4 \cdot 51 \\
(4 \cdot 35 \text { to } 4 \cdot 66)\end{array}$ \\
\hline 3 & C & 32 & 53 & 62 & 37 & $\begin{array}{l}6 \cdot 19 \\
(6.03 \text { to } 6 \cdot 35)\end{array}$ & $\begin{array}{l}0.0149 \\
(0.0111 \text { to } 0.0186)\end{array}$ & $\begin{array}{l}15.63 \\
(12.67 \text { to } 18.58)\end{array}$ & $\begin{array}{l}1.764 \\
(0.5356 \text { to } 2.992)\end{array}$ & $\begin{array}{l}4286 \\
\text { (3693 to } 4880)\end{array}$ & $\begin{array}{l}3 \cdot 89 \\
(3 \cdot 64 \text { to } 4 \cdot 12)\end{array}$ & $\begin{array}{l}4 \cdot 62 \\
(4 \cdot 44 \text { to } 4 \cdot 77)\end{array}$ \\
\hline 4 & C & 35 & 100 & 42 & 60 & $\begin{array}{l}7 \cdot 86 \\
(7 \cdot 79 \text { to } 7 \cdot 93)\end{array}$ & $\begin{array}{l}0.0059 \\
(0.0009 \text { to } 0.0110)\end{array}$ & $\begin{array}{l}20.42 \\
(16.43 \text { to } 24.41)\end{array}$ & $\begin{array}{l}2.010 \\
(0.3538 \text { to } 3.666)\end{array}$ & $\begin{array}{l}3822 \\
(3022 \text { to } 4622)\end{array}$ & $\begin{array}{l}4 \cdot 44 \\
(4 \cdot 25 \text { to } 4 \cdot 61)\end{array}$ & $\begin{array}{l}4 \cdot 77 \\
(4 \cdot 61 \text { to } 4 \cdot 90)\end{array}$ \\
\hline 5 & SR & 26 & 84 & 46 & 85 & $\begin{array}{l}7 \cdot 68 \\
(7 \cdot 54 \text { to } 7 \cdot 82)\end{array}$ & $\begin{array}{l}0.0056 \\
(0 \text { to } 0.0111)\end{array}$ & $\begin{array}{l}25.61 \\
(21.20 \text { to } 30.02)\end{array}$ & $\begin{array}{l}3.206 \\
(1.375 \text { to } 5.037)\end{array}$ & $\begin{array}{l}4274 \\
\text { (3390 to } 5159)\end{array}$ & $(3 \cdot 90$ to $4 \cdot 43)$ & $\begin{array}{l}4 \cdot 72 \\
(4 \cdot 51 \text { to } 4 \cdot 89)\end{array}$ \\
\hline 6 & $\mathbf{R}$ & 60 & 90 & 42 & 70 & $\begin{array}{l}6 \cdot 86 \\
(6 \cdot 80 \text { to } 6 \cdot 92) \\
F(5,295)=79 \cdot 28 \\
p<0.001\end{array}$ & $\begin{array}{l}0.0070 \\
(0.0032 \text { to } 0.0108) \\
F(5,77)=3.795 \\
p<0.01\end{array}$ & $\begin{array}{l}25 \cdot 22 \\
(22 \cdot 18 \text { to } 28 \cdot 25) \\
\mathrm{F}(5,77)=6.602 \\
\mathrm{p}<0.001\end{array}$ & $\begin{array}{l}4.769 \\
(3.509 \text { to } 6.029) \\
F(5,77)=3.157 \\
p<0.05\end{array}$ & $\begin{array}{l}5026 \\
(4417 \text { to } 5635) \\
F(5,77)=1.958 \\
0.05<p<0.10\end{array}$ & $\begin{array}{l}3.96 \\
(3 \cdot 79 \text { to } 4.12) \\
\mathrm{F}(5,295)=8.165 \\
\mathrm{p}<0.001\end{array}$ & $\begin{array}{l}4 \cdot 73 \\
(4 \cdot 62 \text { to } 4 \cdot 83) \\
5 \text { F }(5,295)=2 \cdot 137 \\
\text { NS }\end{array}$ \\
\hline
\end{tabular}

OP, operator; GR, grade of operator; C, consultant; SR, senior registrar; R, registrar; No, number of cases performed; LAB 1 (\%), percentage of cases performed in catheter laboratory 1 . Figures are mean $(95 \% \mathrm{CI}) \mathrm{F}, \mathrm{p}$ values $=\mathrm{F}$ value for stated degrees of freedom and corresponding $\mathrm{p}$ values indicating significance across all six $\mathrm{C}_{\mathrm{b}}$ operators.

Table 8 Differences between the two catheter laboratories

\begin{tabular}{|c|c|c|c|c|}
\hline & Lab 1 & Lab 2 & $t(D F)$ & $p$ \\
\hline Number of cases & 211 & 79 & & \\
\hline Hand $(\%)$ & 49 & 47 & & \\
\hline Brachial (\%) & 75 & 78 & & \\
\hline DAPM reading ( $\left.\mathrm{rad} . \mathrm{cm}^{2}\right)$ & $3476(3160$ to 3791$)$ & $5211(4868$ to 5555$)$ & $t(81)=7.445$ & $<0.001$ \\
\hline $\begin{array}{l}\text { Radiation (mSv) } \\
\text { exposure/case }\end{array}$ & $0.0064(0.0037$ to 0.0090$)$ & $0.0098(0.0069$ to 0.0127$)$ & $t(81)=1 \cdot 740$ & $0.05<\mathrm{p}<0.10$ \\
\hline Procedure time (min) & 20.08 (17 to $78: 22 \cdot 77)$ & $19.59(17.09$ to 22.09$)$ & $t(81)=0.288$ & NS \\
\hline Screening time (min) & $2.895(2.021$ to 3.770$)$ & $2.499(1.548$ to 3.451$)$ & $t(81)=0.613$ & NS \\
\hline LCA opacity & $4.01(3.91$ to 4.11$)$ & $4.03(3.91$ to 4.14$)$ & $\mathrm{t}(299)=0.136$ & NS \\
\hline RCA opacity & $4 \cdot 71(4 \cdot 65$ to $4 \cdot 77)$ & $4.68(4.58$ to 4.78$)$ & $t(299)=0.403$ & NS \\
\hline
\end{tabular}

Figures are mean $(95 \% \mathrm{CI})$.

Table 9 Comparison of results with injection by the femoral and brachial routes (mean and 95\% confidence intervals)

\begin{tabular}{|c|c|c|c|c|}
\hline & \multicolumn{2}{|l|}{ Route } & \multirow[b]{2}{*}{$t(d f)$} & \multirow[b]{2}{*}{$p$} \\
\hline & Brachial & Femoral & & \\
\hline Procedure time ( $\mathrm{min}$ ) & $21.75(19.87$ to 23.62$)$ & $15.46(12.61$ to $18 \cdot 31)$ & $t(81)=3.682$ & $<0.001$ \\
\hline LCA opacity & $4 \cdot 11(4 \cdot 02$ to $4 \cdot 20)$ & $3.71(3.52$ to 3.88$)$ & $\mathrm{t}(299)=4 \cdot 115$ & $<0.001$ \\
\hline RCA opacity & $4 \cdot 75(4 \cdot 70$ to $4 \cdot 81)$ & $4.53(4.40$ to 4.64$)$ & $\mathrm{t}(299)=3.509$ & $<0.001$ \\
\hline $\begin{array}{l}\text { Radiation (mSv) } \\
\text { exposure/case }\end{array}$ & $0.0080(0.0056$ to 0.0104$)$ & $0.0078(0.0042$ to 0.0115$)$ & $t(81)=0.081$ & NS \\
\hline Screening time (min) & $2.948(2 \cdot 182$ to $3 \cdot 714)$ & $2 \cdot 171(1 \cdot 004$ to $3 \cdot 338)$ & $t(81)=1 \cdot 114$ & NS \\
\hline DAPM reading $\left(\mathrm{rad} . \mathrm{cm}^{2}\right)$ & 4379 (4021 to 4737$)$ & 4019 (3474 to 4565$)$ & $t(81)=1.01$ & NS \\
\hline $\begin{array}{l}\text { Catheter calibre } \\
\text { (French gauge) }\end{array}$ & $7 \cdot 22(7 \cdot 16$ to $7 \cdot 29)$ & $5.84(5.73$ to 5.95$)$ & $t(299)=20.973$ & $<0.001$ \\
\hline
\end{tabular}

LCA, left coronary artery; RCA, right coronary artery.

\section{Comparison of catheter gauge}

The differences in arterial opacity score between the catheter gauges were more pronounced in the left coronary artery (table 11). In the left coronary artery gauge 6 gave the lowest scores, increasing scores were obtained in order by gauges 5,7 , and 8 . The differences between all four gauges were statistically significant. Though the trends were similar for the right coronary artery the only significant difference was between gauges 6 and 7.

Table 10 Differences in opacity score and gauge (mean $(95 \%$ CI)) for different catheter types

\begin{tabular}{|c|c|c|c|c|}
\hline Cath & $n$ & Cath gauge (FG) & LCA opacity score & $R C A$ opacity score \\
\hline $\begin{array}{l}\text { C } \\
\text { J } \\
\text { NIH } \\
\text { S } \\
\text { TB } \\
\text { TF }\end{array}$ & $\begin{array}{r}161 \\
71 \\
2 \\
48 \\
22 \\
5\end{array}$ & $\begin{array}{l}6.99(6.93 \text { to } 7.05) \\
5.80(5.71 \text { to } 5.89) \\
7.00(6.49 \text { to } 7.51) \\
7.94(7.83 \text { to } 8.00) \\
7.41(7.26 \text { to } 7.56) \\
6.40(6.08 \text { to } 6.72) \\
F(5,295)=217.6 \\
\text { p }<0.001\end{array}$ & $\begin{array}{l}4.07(3.96 \text { to } 4 \cdot 18) \\
3.70(3.51 \text { to } 3 \cdot 88) \\
4 \cdot 24(3.14 \text { to } 4.91) \\
4.28(4.09 \text { to } 4.45) \\
4.03(3.72 \text { to } 4.31) \\
3.76(3.00 \text { to } 4.37) \\
F(5,295)=4.210 \\
\text { p }<0.01\end{array}$ & $\begin{array}{l}4.77(4.70 \text { to } 4.84) \\
4.53(4.40 \text { to } 4.65) \\
5.00(5.00 \text { to } 5 \cdot 00) \\
4.76(4.63 \text { to } 4 \cdot 88) \\
4.56(4.32 \text { to } 4 \cdot 76) \\
4.44(3.83 \text { to } 4 \cdot 86) \\
F(5,295)=3 \cdot 490 \\
\text { p }<0.01\end{array}$ \\
\hline
\end{tabular}

C, castillo; J, Judkins; NIH, National Institutes of Health; S, Sones; TB, more than one type of catheter from the brachial route; $\mathrm{TF}$, more than one type of catheter from the femoral route; $\mathrm{n}=$ number of cases. $\mathrm{F}$ values for states degrees of freedom and corresponding $\mathrm{p}$ values are given.
Effect of contrast volume

There was a weak but statistically significant negative correlation $(\mathrm{r}=-0 \cdot 132, \mathrm{p}=0.008)$ between contrast volume and left coronary opacity score: no correlation was seen with the right coronary opacity scores. This suggests that opacity was poorer when larger volumes of contrast were used. With each increase of $10 \mathrm{ml}$ in the volume of contrast used there was a decrease of 0.073 in the opacity score.

Election of hand injection against randomisation code

The protocol allowed the operator to override the randomisation code when mechanical injection had been allocated. This occurred in 38 of 155 cases (table 12).

\section{Discussion}

Exposure to ionising radiation is hazardous. Small doses give rise to stochastic effects such as genetic and somatic (carcinogenic) effects. For such effects there is no threshold dose but the probability of the effect occurring is 
Table 11 Comparison of arterial opacity according to catheter gauge (mean (95\% CI))

\begin{tabular}{|c|c|c|c|c|}
\hline Cath gauge & $n$ & Brachial (\%) & LCA opacity score & RCA opacity score \\
\hline $\begin{array}{l}5 \\
6 \\
7 \\
8\end{array}$ & $\begin{array}{r}17 \\
63 \\
176 \\
52\end{array}$ & $\begin{array}{r}0 \\
8 \\
100 \\
100\end{array}$ & $\begin{array}{l}3.93(3.55 \text { to } 4.25) \\
3.66(3.45 \text { to } 3.86) \\
4.06(3.96 \text { to } 4.17) \\
4.25(4.07 \text { to } 4.40) \\
F(3,297)=6.978 \\
\text { p }<0.001\end{array}$ & $\begin{array}{l}4.56(4.28 \text { to } 4.79) \\
4.55(4.41 \text { to } 4.68) \\
4.78(4.71 \text { to } 4.84) \\
4.65(4.51 \text { to } 4.77) \\
\mathrm{F}(3,297)=4.163 \\
\mathrm{p}<0.01\end{array}$ \\
\hline
\end{tabular}

Figures are mean ( $95 \%$ confidence intervals); $n=$ number of cases.

$\mathbf{F}$ values for stated degrees of freedom and corresponding $p$ values are given.

Table 12 Reasons for use of hand injection during any part of a procedure randomised to mechanical injection

\begin{tabular}{lr}
\hline Reason & Cases \\
\hline Small/blocked RCA & 21 \\
Empty pump reservoir & 6 \\
$\begin{array}{l}\text { Actual or suspected } \\
\text { LCA mainstem }\end{array}$ & 6 \\
lesion & \\
$\begin{array}{l}\text { Unstable or difficult } \\
\text { catheter position }\end{array}$ & 4 \\
Other & 1 \\
Total & 38 \\
\hline
\end{tabular}

related to the size of the dose. Even small doses of radiation are associated with some increase in risk. The most up to date advice on radiation protection, including data on risks, is given in publication 60 of the International Commission on Radiological Protection (ICRP). ${ }^{6}$ Practice in United Kingdom is governed by the Ionising Radiation Regulations (1985, 1988), ${ }^{78}$ while further guidance, to take into account the latest information, is given by the Health and Safety Commission ${ }^{9}$ and National Radiological Protection Board. ${ }^{10}$ The aim of the guidelines is that the risk should be comparable to other "safe", sedentary occupations. The general advice of the ICRP is that doses of radiation should be kept "as low as reasonably achievable" (ALARA principle).

The annual dose limit for the eye for cardiologists is $150 \mathrm{mSv}$, those likely to exceed 45 $\mathrm{mSv}$ per annum should be classified as radiation workers, which entails much more rigorous monitoring and record keeping. ${ }^{7}$

We estimated the eye dose with film badge dosimeters attached to the cardiologist's hat. We chose film badges rather than lithium fluoride thermoluminescence dosemeters because they are up to five times more sensitive at diagnostic $x$-ray energies.

Our data show that the use of the mechanical injector pump reduced in radiation exposure to half that with hand injection.

At an annual case load consisting entirely of 500 diagnostic coronary angiograms eye doses of $0.011 \mathrm{mSv}$ for hand injection and $0.005 \mathrm{mSv}$ for mechanical injection give annual doses of $5.5 \mathrm{mSv}$ and $2.6 \mathrm{mSv}$ respectively, which are well within the dose limits even for members of the public. The spread of doses was much greater with hand injection. The upper $95 \%$ confidence intervals of the measurements $(0.138 \mathrm{mSv}$ and 0.0078 $\mathrm{mSv}$ ) give annual doses of $69 \mathrm{mSv}$ and 3.9 $\mathrm{mSv}$ for hand injection and mechanical injection respectively. The value for hand injection would require classification as a radiation worker.

The brachial route, which is routinely used in our department, was used in $76 \%$ of cases. Five of the six operators we studied routinely use the brachial route for diagnostic studies. The mean dose per case was the same for brachial and femoral examinations (table 9). The wider confidence intervals for the femoral route reflect a smaller number of cases and fewer cases per film badge.

Hand and mechanical injection gave arterial opacity of a similar quality. This does not confirm previous suggestions that the more consistent pressures and flow rates generated by the pump produce better opacification. ${ }^{3}$ The right coronary artery was consistently better opacified than the left by both injection techniques. This may be because of the simpler anatomy of the right coronary or its smaller volume and blood flow. Perhaps the volumes and flow rates that we have routinely used with mechanical injection for both arteries $(7 \mathrm{ml}$ at $5 \mathrm{ml} / \mathrm{s})$ should be increased for the left coronary artery. Mechanical injection did not increase the procedure time or the inconvenience.

There were more complications in the hand injected group but only one complication (emergency coronary artery bypass grafting) that might have been related to the technique of coronary artery injection. This is reassuring, but this study is too small to assess safety, given the low overall mortality and morbidity of coronary arteriography. In several larger series $\left(1500,{ }^{11} 6000,{ }^{12} 18000^{13}\right.$ patients), however, mechanical injection had acceptable complication rates that resembled other published series. In addition several operators at our centre have used mechanical injection for some years without problems. In several cases (38 out of 155 (table 12) hand injection was used during part of a study randomised to mechanical injection. Often this was because the situation was perceived as requiring more caution (such as a small or blocked right coronary artery or a possible left mainstem lesion). This can be compensated for by reducing the flow rate setting of the pump appropriately, but in this situation most operators preferred to be in control of the catheter tip as well as the flow rate and injections were given by hand.

The data were also examined for other factors which might have affected the radiation exposure or opacity score. Possible factors were the route of arterial access, catheter type and gauge, the operator, and catheter laboratory.

There were statistically significant differences in radiation exposure between the operators and between the two catheter laboratories. Operator 3 had a higher mean radiation exposure than the others (table 7). The most likely explanation for this was the dissimilarities between the groups studied. Operator 3 performed more cases by hand than his colleagues and also did more procedures in catheter laboratory 2 .

- Catheter laboratory 2 was associated with a higher operator dose per case and a higher DAPM reading than catheter laboratory 1 (table 8 ). The difference in DAPM reading indicates that more radiation was emitted per case in catheter laboratory 2: this probably explains the higher radiation exposure. The likely reason for this lies in technical factors peculiar to the laboratories. In catheter laboratory 1 during magnified cine filming (which is used for coronary arteriography but not left ventriculography) the image brightness is maintained by means of a smaller field and a larger camera aperture while the radiation output is kept constant. In catheter laboratory 
2 the image brightness is maintained by an increase in the radiation output (this difference would result in 2.25 times more radiation being used per frame under equivalent circumstances in laboratory 2 ). In addition the pulse width in laboratory 1 is $5.0 \mathrm{~ms}$ compared with $6.0 \mathrm{~ms}$ in laboratory 2 , and the intensifier conversion factor is higher in laboratory 1 . Both these differences would give higher radiation doses per frame in laboratory 2. These factors are only partly offset by the higher frame rate of catheter laboratory 1 (table 3).

The factors which produced statistical differences in arterial opacity score were: operator, access route, catheter gauge, and catheter type.

The operator whose scores were the highest operated exclusively from the brachial route, predominantly used Sones type catheters, and had the largest average catheter gauge (tables 7,9 and 10). The operator with the lowest scores operated exclusively from the femoral route with predominantly Judkins catheters and had the smallest average catheter gauge. Among the other operators the opacity scores and mix of arterial access route, catheter types, and mean catheter gauge were intermediate. In keeping with this the brachial route produced a higher mean opacity score than the femoral route, brachial catheter types produced a higher mean score than femoral type catheters, and larger gauge catheters, tended to produce higher opacity scores than smaller ones. A confounding factor is that the observer though unaware of the mode of injection was aware of the operator, catheter type, and approximate gauge and could deduce the access route. Therefore bias cannot be excluded. In view of these features it is impossible to be confident about what is causing the observed differences between operators. We speculate that catheter gauge may be important with a possible effect of access route (with associated catheter types) and perhaps operator. This study was not principally designed to answer these questions and further work would be necessary to clarify this.

Procedural variables (procedure time, screening time, and DAPM reading) differed between operators. This was not unexpected: broadly the differences seem to be explained by operator experience-more experienced operators had shorter procedure times and used less screening time. The least experienced operator with the longest screening time had a higher mean DAPM reading than the others, though this was not reflected in his radiation dose per case.

The negative correlation between contrast volume and opacity score was surprising. An explanation for the negative correlation may be that when arterial opacity is poor because of poor catheter engagement, large patient mass, or other factors, the operator takes further views and increases the contrast flow rate.

The use of a mechanical injector pump for coronary arteriography halved cardiologist radiation exposure. This technique is safe, convenient, and produces angiograms of comparable quality to hand injection. In view of the advantages and the absence of drawbacks, we believe that mechanical injection of contrast during selective coronary arteriography should be standard practice.

We thank the cardiac radiographers of Wythenshawe Hospital, without whose help the study would not have been possible; and Dr C L Bray, Dr C Ward, and Dr N H Brooks for allowing their patients to be studied. They and Dr R D Levy and Dr W E Rhoden performed the angiograms.

Chamberlain D, Oldershaw P. British Cardiac Society Newsletter. Br Hean ₹ 1992;67:278.

2 Grant SCD, Bennett DH, Mather JM. Reduction of radiation exposure to the cardiologist during coronary angiography by the use of a remotely controlled mechanical pump for injection of contrast medium. Cathet Cardiovasc Diagn 1992;25:107-9.

3 Gardiner GA, Meyerovitz MF, Boxt LM, et al. Selective coronary angiography using a power injector. $A \mathcal{F}$ 1986;146:831-3.

4 Talley JD, Smith SM, Walton-Shirley M, et al. A prospective randomised study of $4 \cdot 1$ French catheters utilising the percutaneous right brachial approach for the diagnothe percutaneous right brachial approach for the diagnosis of coronary

5 Aitken M, Anderson D, Francis B, Hinde J. Statistical Modelling in GLIM. Oxford: Clarendon Press, 1989.

Modelling in GLIM. Oxford: Clarendon Press, 1989.
ICRP. Recommendations of the International Commission on Radiological Protection 1990 Publication 60. Oxford: Pergamon Press, 1990.

7 The ionising radiations regulations 1985. Statutory Instrument No 1333. London: HMSO.

8 The Ionising Radiation (Protection of Persons Undergoing Medical Examination or Treatment) Regulation 1988. Statutory Instruments 1988 No. 778 London: HMSO.

9 Health and Safety Commission 1991 Dose limitationrestriction of exposure. Approved code of practice. Part 4 London: $\mathrm{HMSO}$.

10 NRPB 1991 Consultative Document. Board advice following publication of the 1990 recommendations of the ICRP. NRPB-M321. Chilton: NRPB

11 Koppes GM. Complication rate of power coronary angiography injection. Angiology 1980;31:130-5.

12 Ireland MA, Davis MJE, Hockings BEF, Gibbons F Safety and convenience of a mechanical injector pump for coronary angiography. Cathet Cardiovasc Diagn 1989;16:199-201.

13 Goss JE, Ramo BW, Raff GL, et al. Power injection of contrast medial during percutaneous transluminal coronary, artery angioplasty. Cathet Cardiovasc Diagn 1989; 15:195-8. 